\title{
Algorithm Design for the Novel Mechatronics Electro-hydraulic Driving System: Micro-Independent Metering
}

\author{
$1^{\text {st }}$ Karem Abuowda \\ Researcher of Electro-hydraulic manipulation \\ Bournemouth university \\ Poole, UK \\ kabuowda@bournemouth.ac.uk
}

\author{
$2^{\text {nd }}$ Siamak Noroozi \\ Advanced technology centre \\ Bournemouth University \\ Poole, UK \\ snoroozi@bournemouth.ac.uk
}

\author{
$3^{\text {rd }}$ Mihai Dupac \\ Advanced technology centre \\ Bournemouth University \\ Poole, UK \\ mdupac@bournemouth.ac.uk
}

\author{
$4^{\text {th }}$ Phil Godfrey \\ Engineeing director \\ Hydreco Hydraulics Ltd \\ Poole, UK \\ pgofrey@hydreco.com
}

\begin{abstract}
This paper presents a control algorithm for a novel Mechatronics Electro-hydraulic Driving System, MicroIndependent Metering. The main idea of the independent metering is a separated control of the hydraulic actuator ports which are the meter-in and the meter-out. IM technique configuration relies upon different types of valves, especially on poppet valves. As these valves have stability limitations, a novel stepped rotary valve was developed to configure a novel IM form. This form is termed as micro-independent metering due to the activation technique of the valve. A novel algorithm was developed to control this new configuration. The algorithm implements the rules of the independent metering using the new valve. It is able to detect the different operation modes and make a real time changing between them. Also, it activates the enhanced performance technique which was especially developed for this new configuration. The paper includes the mathematical analysis of the developed algorithm and its State-flow representation. Also, it includes the simulation of the system performance, and the effect of MIM on the cylinder velocity.
\end{abstract}

Index Terms-Micro-Indpendent Metering, Indpendent Metering, Programable valves, Hydro-mechatronics.

\section{INTRODUCTION}

Hydraulic systems have been widely used due to their significant properties such as high power density, flexibility, and high stiffness [1]. Their applications are ranging from military, aerospace, industrial and earth moving machines. Energy saving and controlability are important concerns in these driving systems [2], [3]. Different systems have been developed to enhance the hydraulic drives performance. In the light of a hydraulic circuit, inlet and outlet ports of the cylinder, which are the meter-in and the meter-out, are mechanically connected when the used control valve is a traditional spool type. Due to this connection, a hydraulic drive has one degree of freedom, which means that one chamber pressure is controlled. Separating the meter-in and meter-out ports increases the system flexibility, reduces energy losses and grants implementing advanced control methods or algorithms [4]-[6]. The formed configuration, based on ports separation, is called Independent Metering (IM). Different control systems were developed to implement IM, [2]. For example, mathematical analysis for the four valve separate metering [7] and the analysis of their discrete five operation modes are in [8]. Shenouda designed three valve modulation modes. These modes are continuous and include the five discrete modes [9]. Likewise, the five valves architecture of IM was investigated in [10] and [11]. The additional valve enables precise control of direct cross port flow. Moreover, Modiciency control algorithm was developed for the five valves scheme [12]. However, hybrid hydraulic driving system which relies on three pressure lines, high, medium and tank can form IM [5]. Regarding the digital hydraulic, a digital Flow Control Unit (DFCU) is a unit that connects a group of on/off valves in a parallel layout and their response is presented proportionally. Using the digital flow control unit to the IM system adds extra advantages to the traditional IM that uses poppet or spool valves, [13]. It doesn't require active pressure control similar to traditional systems [14].

The poppet valve is the main valve used to form IM [15], but this valve has some disadvantages such as instability and low flow rate [16], [17], which results in lack of industrial spreading of this type. However, a new rotary flow control orifice has been developed to be used in high flow rate applications [18]. Evolve a stepped rotary valve using this orifice, similar to [19], leads to pattern a new configuration of IM, thus a novel control system or algorithm can be established. The new IM configuration is called micro-independent metering (Fig 1). The micro term is due to the activation technique of the stepper motor in the design. 


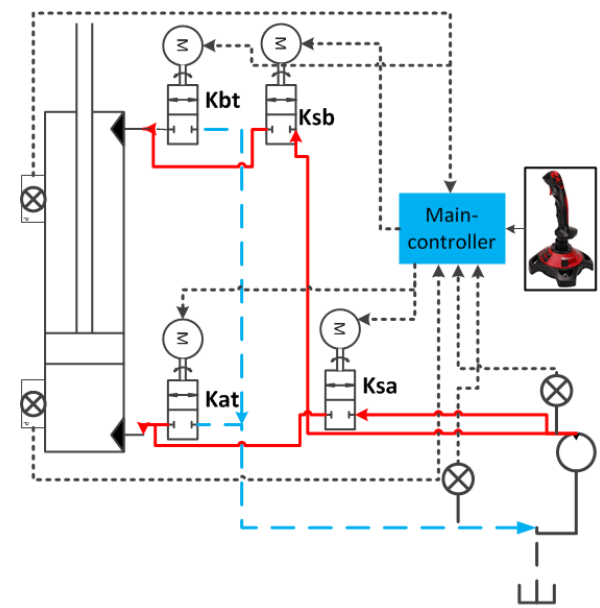

Fig. 1. The main configuration of the novel system micro- independent metering system

This paper presents the main algorithm developed to control the new independent metering configuration. It also, discusses the activation rules of different operation mode, the mode switching, and the enhanced performance technique. It is organized as follow: in Section 2, the operation modes are analyzed and physically represented. In Section 3, the MicroIndependent Metering algorithm is explained in details. In Section 4, the State-flow diagram of the algorithm is included. Also, the results of the modeling and simulation are evaluated. The conclusion is presented in Section 5.

\section{THE INDEPENDENT METERING OPERATING MODES}

There are five operations modes of the IM which are Power Extension (PE), Power Retraction (PR), High side regeneration extension (HSRE), low side regeneration retraction (LSRR), and Low side extension (LSRE). The power extension and retraction are the most power consumer. while other modes regenerate energy from the cylinder chamber to the another. In this section, the operation modes are physically represented. Firstly, the PE is performed by supplying fluid from the pump to the actuator head chamber using inlet port, while the fluid is drained from the actuator to the tank using the outlet branch. The next operation mode is PR which is the opposite of the PE. These two modes are illustrated in Fig 2.

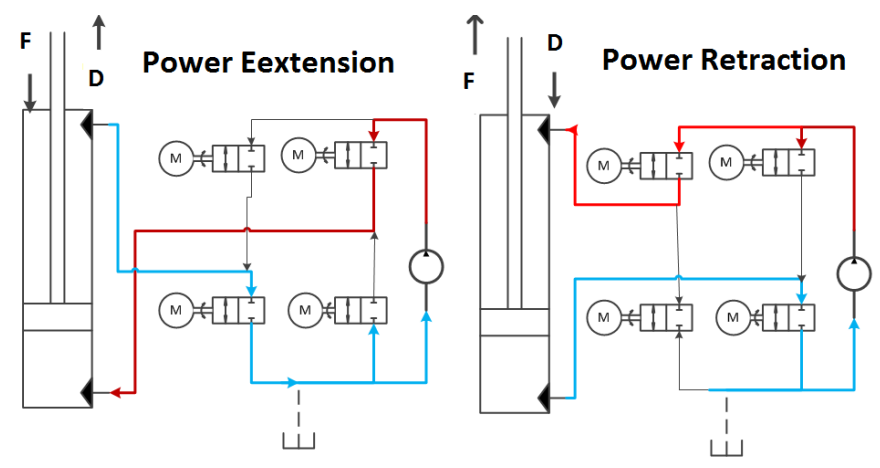

Fig. 2. The physical representation of PE and PR modes. Where $F$ is force, $\mathrm{d}$ is direction. The red line is the pumped line, and the blue is the tank line.
Regeneration modes are separated into high side and low side. The HSRE is shown in Figure 3. The regeneration is achieved when the fluid is passed from the rod chamber to the head chamber using the high connection point of the bridge. If the recirculated flow is not enough, the difference is supplied by the pump itself, [9].

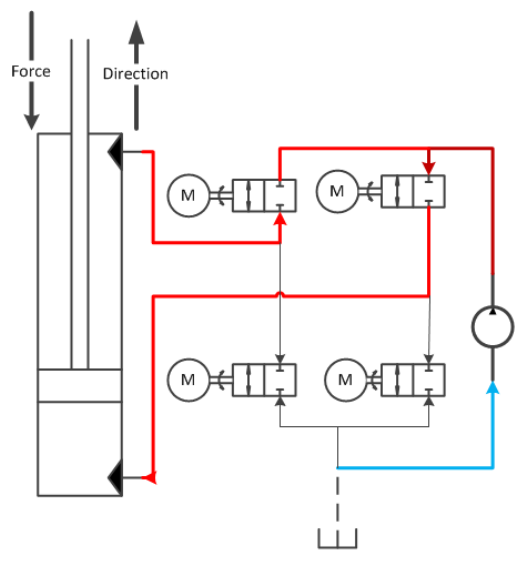

Fig. 3. The HSRE mode where the fluid flows from the outlet to the inlet with some flow from the main pump as required.

The low side regeneration appears when the fluid regeneration is performed at the low connection point. The low side regeneration has two modes which are the LSRR mode and the LSRE mode. The LSRE happens when the load is moving up and the gravity is being resisted. The LSRR happens when load is moving down using its gravity. The modes are shown in Fig 4.

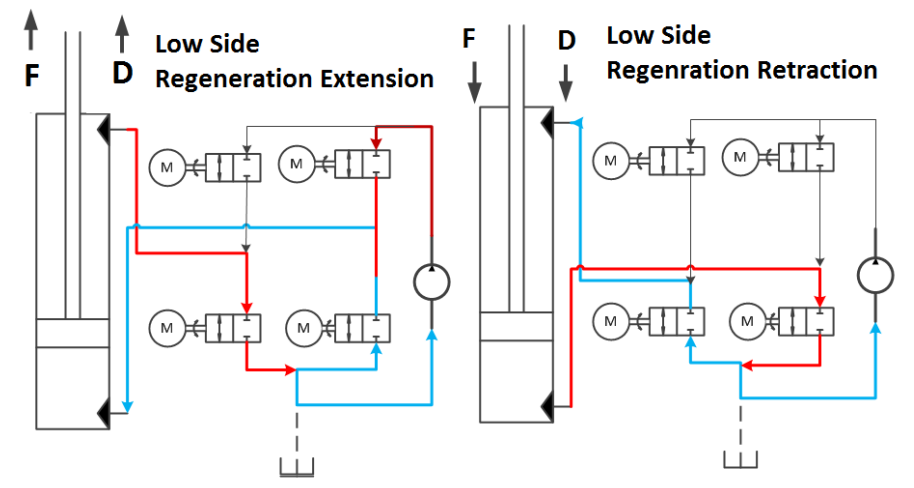

Fig. 4. The low side regeneration extension where some power is required from the pump.

The force and velocity limits of the five mode are shown in Fig 5. As noticed in the same Fig, the PE and the HSRE are in the first quadrant, and their power and velocity limits as written in [20] are as follows:

$$
\begin{aligned}
& {\left[F_{P E}, V_{P E}\right]=\left[P_{s, \text { max }} \cdot A_{a}, \frac{q_{s, \text { max }}}{A_{a}}\right]} \\
& {\left[F_{H S R E}, V_{H S R E}\right]=\left[P_{s, \max } \cdot\left(A_{a}-A_{b}\right), \frac{q_{s, \text { max }}}{\left(A_{a}-A_{b}\right)}\right]}
\end{aligned}
$$


Where $F$ is a force, $V$ is the velocity, $q$ is the pump fluid flow, $A_{a}$ is the head chamber area, $A_{b}$ is the rod chamber area.

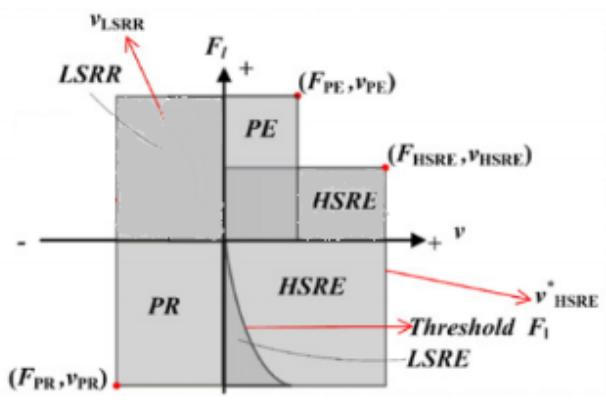

Fig. 5. The IM operation modes speed and force limitations.

The second quadrant includes the LSRR. Its power and velocity limits can be describe according to,

$$
\left[F_{L S R R}, V_{L S R R}\right]=\left[F_{l}, \frac{q_{L S R R}}{A_{b}}\right]
$$

The PR mode and the LSRE mode performance limits are represented by,

$$
\begin{aligned}
& {\left[F_{P R}, V_{P R}\right]=\left[P_{s, \max } \cdot A_{b}, \frac{q_{s, \max }}{A_{b}}\right]} \\
& {\left[F_{L S R E}, V_{L S R E}\right]=\left[F_{l} \cdot A_{b}, \min \left(\frac{q_{L S R E 1}}{A_{a}}, \frac{q_{L S R E 2}}{A_{b}}\right)\right]}
\end{aligned}
$$

Modes selection depends on the applied force given by Equation 6. The force value and the speed value and direction determine if the mode is extension or retraction. If the speed is negative and the force is negative then the mode is LSRR, but when the force is positive, the mode is PR. If the speed is positive and the force is positive, the mode is LSRE. If the force is negative direction then the limits between the PE and the HSRE is represented by the direction of the high side pressure in Equation 7. If the HPS in Equation 7 is positive and more than the absolute value of the force then the mode is PE, otherwise, the mode is HSRE.

$$
\begin{aligned}
& F=\left(-P_{a} * A_{a}+P_{b} * A_{b}\right) \\
& H P S=P s *\left(A_{a}-A_{b}\right)
\end{aligned}
$$

\section{Micro-IndePendent Metering Algorithm}

The MIM algorithm is based on the assumption that the system dynamic changes slowly, and the capacity of the hydraulic cylinder and lines are neglected. Based on the assumptions, the system can be represented as shown in Fig 6. Where $K_{e q}$ is the equivalent flow from the two valves through the cylinder, $P_{e q}$ is the equivalent pressure, $K_{s a}$ is the valve between the pump and the cylinder, $K_{b t}$ is the valve between the cylinder and the tank, $P_{s}$ is the pressure source, $A_{a}$ is the head chamber area, $P_{a}$ is the head chamber pressure, $P_{b}$ is the back chamber pressure, and $A_{b}$ is the back chamber pressure.

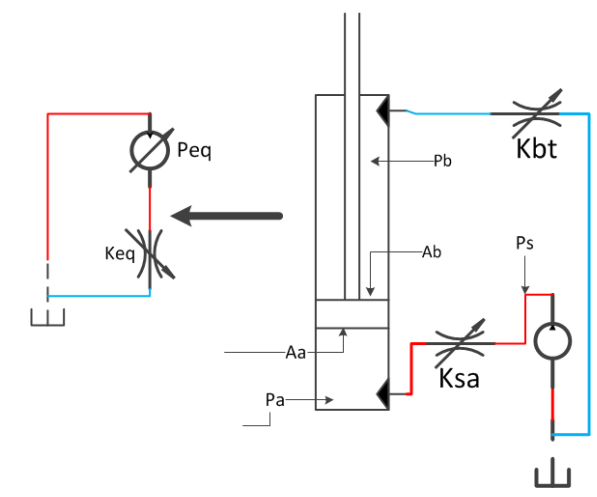

Fig. 6. The low side regeneration extension where some power is required from the pump.

The algorithm contains three stages. The first stage is fixing the stepper driver resolution. The second stage defines the suitable mode and the required flow from each valve to reach the required velocity. Determining the suitable mode is based on the limits described in Section 2. After that, the selected valves can be Off or On where the On condition can be triggered using the step detection or based on the enhanced performance activation. Equations 8 to 12, are used to determine the overall equivalent flow for the modes PE, PR, HSRE, LSRE, and LSRR, respectively.

$$
\begin{aligned}
K_{e q} & =\frac{A_{b} \dot{x}}{\sqrt{\left(R P_{s}-P_{r}\right)+\left(-R P_{a}+P_{b}\right)}} \\
K_{e q} & =-\frac{A_{b} \dot{x}}{\sqrt{\left(P_{s}-R P_{r}\right)+\left(-P_{b}+R P_{a}\right)}} \\
K_{e q} & =\frac{A_{b} \dot{x}}{\sqrt{(R-1) P_{s}+\left(-R P_{a}+P_{b}\right)}} \\
K_{e q} & =\frac{A_{b} \dot{x}}{\sqrt{(R-1) P_{r}+\left(-R P_{a}+P_{b}\right)}} \\
K_{e q} & =-\frac{A_{b} \dot{x}}{\sqrt{-(R-1) P_{r}+\left(-P_{b}+R P_{a}\right)}}
\end{aligned}
$$

Where, $\dot{x}$ is the velocity, $A_{b}$ is back chamber area, $\mathrm{R}$ is the ration between the head and the back chamber areas, $P_{s}$ is the pressure sourse, $P_{a}$ is the head chamber pressure, $P_{b}$ is the back chamber pressure, and the $P_{r}$ is the tank line pressure.

The conductance of each valve is according to the sensitivity relation which was developed in the patent [21] according to,

$$
\begin{aligned}
K_{a} & =S K b \\
K_{b} & =\frac{\sqrt{S^{2}+R^{3}} K_{e q}}{S}
\end{aligned}
$$

where $S=1.2734$ is a sensitivity coefficient. $K_{a}$ and $K_{b}$ can be changed based on the selected mode, according to Table I.

TABLE I

THE VALVES ACTIVATION

\begin{tabular}{cccccc}
\hline Mode & PE & HSRE & LSRE & LSRR & PR \\
\hline$K a$ & $K s a$ & $K s a$ & $K b t$ & $K a t$ & $K b t$ \\
$K b$ & $K a t$ & $K s b$ & $K a t$ & $K b t$ & $K s a$ \\
\hline
\end{tabular}


After selecting the mode and determining the required conductance for each valve, the stepper motor opening degree should be selected. The opening degree depends on matching the closest value of the motor steps conductance to the value of the required flow from each valve. This is performed using close value detection procedure In this procedure, the full stepping motor activation is used. If the enhanced performance is activated then the micro-stepping is used. At this stage, the value between the closest step value and its next step value can be split into sub-values based on the input. Then, the closest value for the required operation can be detected. Fig 7 illustrates the values of the used valve full stepping (1), 1/4 micro-step (2), and 1/8 micro-step (3).

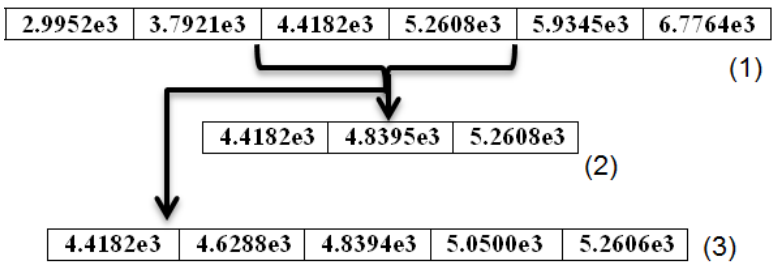

Fig. 7. The flow value based on the opening degree, and how the division using micro stepping technique can be used to find closer value

\section{Modelling AND Simulation}

The MIM algorithm was developed using Simulink and State-flow. As shown in Fig 8, the algorithm reads actuator chambers pressures, and the pump and tank pressures, the speed, the subdivision, and the user switch. The outputs are the mode and the four valve opening degrees. The algorithm starts by measuring the load and by selecting the suitable operation mode. The related state flow diagram is represented in Fig 11(a) in the Appendix A. The produced results are directed to the close value detection procedure which is illustrated in Fig 11(b) in the Appendix A. In this sub-part of the algorithm, there are three activation options which are the No activation, Full stepping, and the Enhanced performance option. In the No activation option, the connection between points (1) to (10), which is the outlet,in Fig 11(b) is activated. The second option is activated from point (1)-(2)-(3)-(10). The third option, which is the enhanced performance has two options. The first is when the calculated conductance value is bigger than the saved value, the activated path is (1)-(2)-(3)-(4)-(7)-(10). If the stored value is more, then the followed path is (1)-(2)-(3)(5)-(9)-(10). The point (2) represents a FOR loop that finds the difference between the stored values for conductance at every step and the required one. (3) is a FOR loop that detect the smallest difference point and based on this, the step that has the lowest difference is selected. The point (4) read the division command from the user and then divide the values between the two main steps which are the selected step and the one after it by moving to point (5), or select the FOR loop at point (7). These two FOR loops are used to find the closest value. The subdivision effect on the MIM performance is illustrated in Fig 10, in the Appendix A. Regarding the performance of the

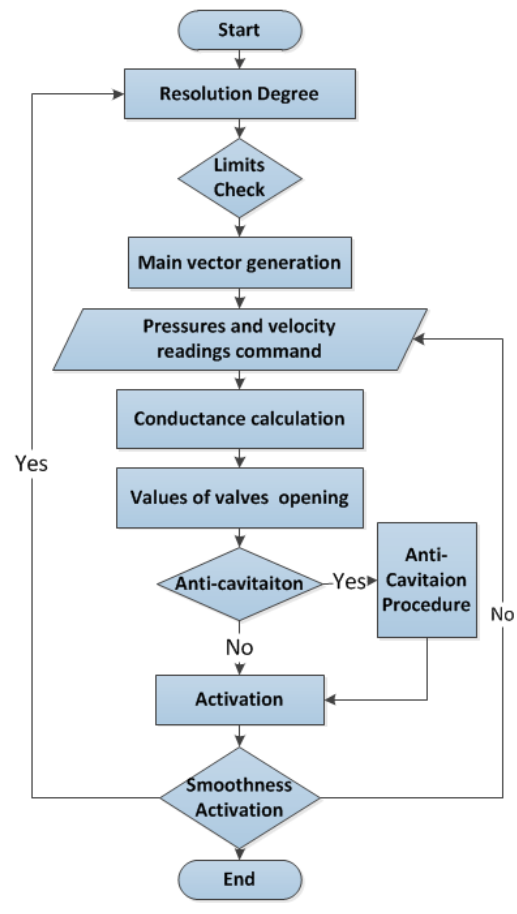

Fig. 8. The flowchart of the MIM algorithm

MIM system comparing with the traditional IM system, which relies on Valvistor valve in [22] and [23]. The comparison was performed using model of hydraulic cylinder to activate power extension mode. As shown in Fig 9, the MIM system is able to reject the effect of the fluid flow disturbances.

\section{CONCLUSION}

The paper presents a control algorithm for the novel hydraulic driving system Micro-Independent Metering. The independent metering technique is based on an a separate control of the hydraulic actuator ports which are the meterin and the meter-out. A novel stepped rotary valve was developed to configure a novel IM form. This form is termed as micro-independent metering due to the activation technique of the valve. This paper explained the developed algorithm for this configuration. The algorithm starts by measuring the required speed and the applied load, then a suitable mode is selected and the required overall flow is evaluated. Based on the calculated flow, the required valves to be activated can be defined and the the conductance values sent to the close value detection where the suitable commands can be transmitted to the motor drivers. The close value detection procedure contains the micro-stepping expansion feature which enhance the performance of the system. Also, it allows the user to change the operation smoothness according to the work requirements. The algorithm showed ability to perform different operation modes and the step division affects the cylinder velocity. Moreover, the MIM simulation showed ability to reject fluid disturbances effect. 


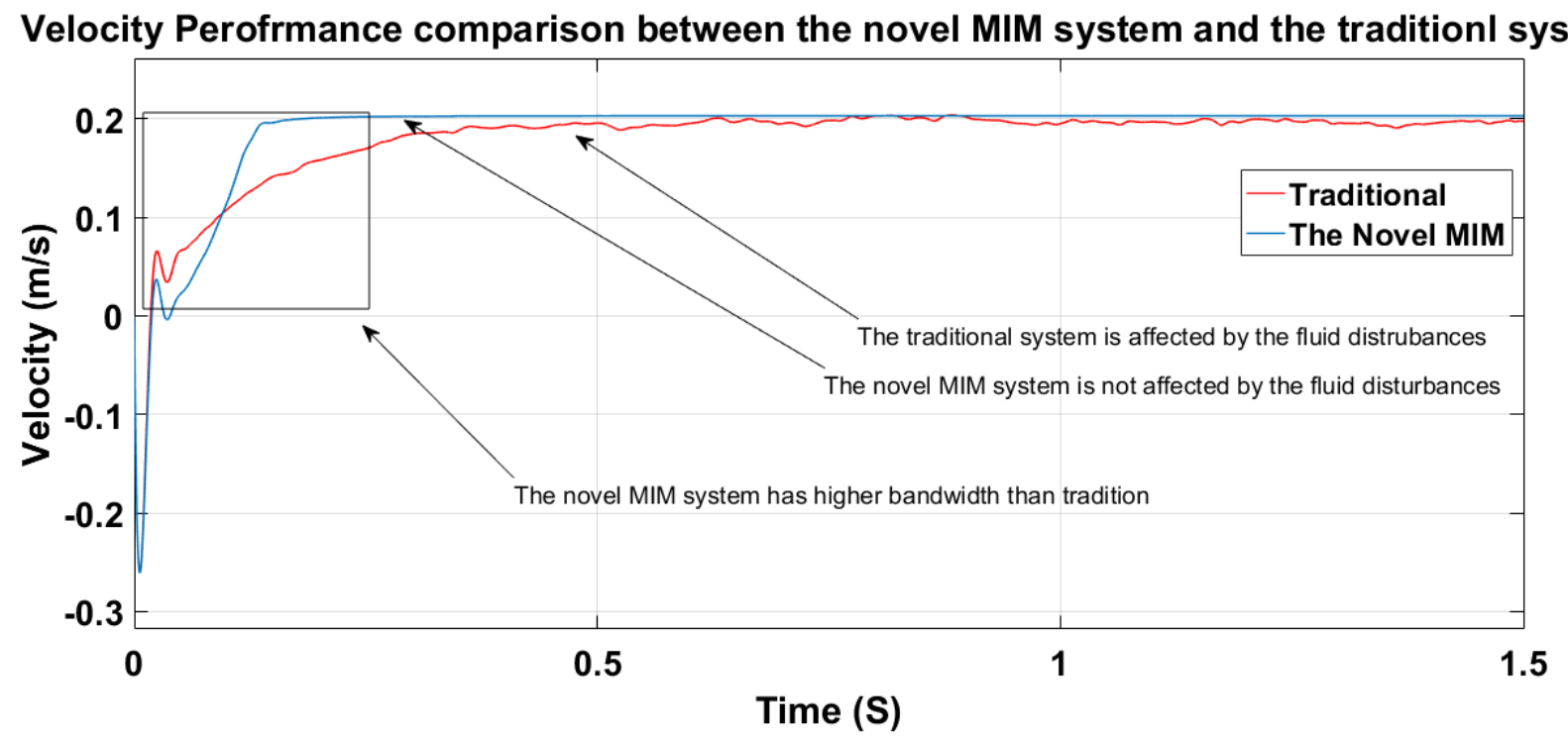

Fig. 9. Velocity control performance between the traditional IM and the MIM. The comparison was by injected noises which simulates the fluid disturbances

\section{REFERENCES}

[1] A. Parr, Hydraulics and pneumatics: a technician's and engineer's guide. Elsevier, 2011.

[2] J. Mattila, J. Koivumäki, D. G. Caldwell, and C. Semini, "A survey on control of hydraulic robotic manipulators with projection to future trends," IEEE/ASME Transactions on Mechatronics, vol. 22, no. 2, pp. 669-680, 2017.

[3] B. Eriksson and J.-O. Palmberg, "Individual metering fluid power systems: challenges and opportunities," Proceedings of the institution of mechanical engineers, part I: journal of systems and control engineering, vol. 225, no. 2, pp. 196-211, 2011.

[4] M. Scherer, M. Geimer, and B. Weiss, "Contribution on control strategies of flow-on-demand hydraulic circuits," in 13th Scandinavian International Conference on Fluid Power; June 3-5; 2013; Linköping; Sweden, no. 092. Linköping University Electronic Press, 2013, pp. 531-540.

[5] M. Vukovic, R. Leifeld, and H. Murrenhoff, "Steam-a hydraulic hybrid architecture for excavators," in 10th International Fluid Power Conference (10. IFK), 2016, pp. 8-10.

[6] A. Sitte and J. Weber, "Structural design of independent metering control systems," in 13th Scandinavian International Conference on Fluid Power; June 3-5; 2013; Linköping; Sweden, no. 092. Linköping University Electronic Press, 2013, pp. 261-270.

[7] K. A. Tabor, "A novel method of controlling a hydraulic actuator with four valve independent metering using load feedback," SAE Technical Paper, Tech. Rep., 2005.

[8] _ - "Optimal velocity control and cavitation prevention of a hydraulic actuator using four valve independent metering," SAE Technical Paper, Tech. Rep., 2005.

[9] A. Shenouda, "Quasi-static hydraulic control systems and energy savings potential using independent metering four-valve assembly configuration," Ph.D. dissertation, Georgia Institute of Technology, 2006.

[10] S. Liu and B. Yao, "Coordinate control of energy saving programmable valves," IEEE Transactions on Control Systems Technology, vol. 16, no. 1, pp. 34-45, 2008.

[11] B. Yao and C. DeBoer, "Energy-saving adaptive robust motion control of single-rod hydraulic cylinders with programmable valves," in American Control Conference, 2002. Proceedings of the 2002, vol. 6. IEEE, 2002, pp. 4819-4824.
[12] G. Kolks and J. Weber, "Modiciency-efficient industrial hydraulic drives through independent metering using optimal operating modes," in Proceedings of the 10th International Conference on Fluid Power, 2016.

[13] M. Ketonen and M. Linjama, "Simulation study of a digital hydraulic independent metering valve system on an excavator," in Proceedings of 15: th Scandinavian International Conference on Fluid Power, June 79, 2017, Linköping, Sweden, no. 144. Linköping University Electronic Press, 2017, pp. 136-146.

[14] M. Linjama and M. Vilenius, "Energy-efficient motion control of a digital hydraulic joint actuator," in Proceedings of the JFPS International Symposium on Fluid Power, vol. 2005, no. 6. The Japan Fluid Power System Society, 2005, pp. 640-645.

[15] P. Opdenbosch, N. Sadegh, W. Book, and A. Enes, "Auto-calibration based control for independent metering of hydraulic actuators," in Robotics and Automation (ICRA), 2011 IEEE International Conference on. IEEE, 2011, pp. 153-158.

[16] O. A. C. O. TWO-STAGE, "Performance limitations of a class of twostage electro-hydraulic flow valves," 2002.

[17] B. Eriksson, "Mobile fluid power systems design: with a focus on energy efficiency," Ph.D. dissertation, Linköping University Electronic Press, 2010

[18] I. Okhotnikov, S. Noroozi, P. Sewell, and P. Godfrey, "Evaluation of steady flow torques and pressure losses in a rotary flow control valve by means of computational fluid dynamics," International Journal of Heat and Fluid Flow, vol. 64, pp. 89-102, 2017.

[19] K. Abuowda, S. Noroozi, M. Dupac, and P. Godfry, "A dynamic model and performance analysis of a stepped rotary flow control valve," Proceedings of the Institution of Mechanical Engineers, Part I: Journal of Systems and Control Engineering, p. 0959651818820978, 2019.

[20] B. Xu, R. Ding, J. Zhang, M. Cheng, and T. Sun, "Pump/valves coordinate control of the independent metering system for mobile machinery," Automation in Construction, vol. 57, pp. 98-111, 2015.

[21] K. A. Tabor, "Velocity based method of controlling an electrohydraulic proportional control valve," Aug. 17 2004, uS Patent 6,775,974.

[22] R. Zhang, A. G. Alleyne, and E. A. Prasetiawan, "Performance limitations of a class of two-stage electro-hydraulic flow valves," International Journal of Fluid Power, vol. 3, no. 1, pp. 47-53, 2002.

[23] Y. Luo, "System modeling and control design of a two-stage metering poppet-valve system," Ph.D. dissertation, University of MissouriColumbia, 2006.

AppendixA 


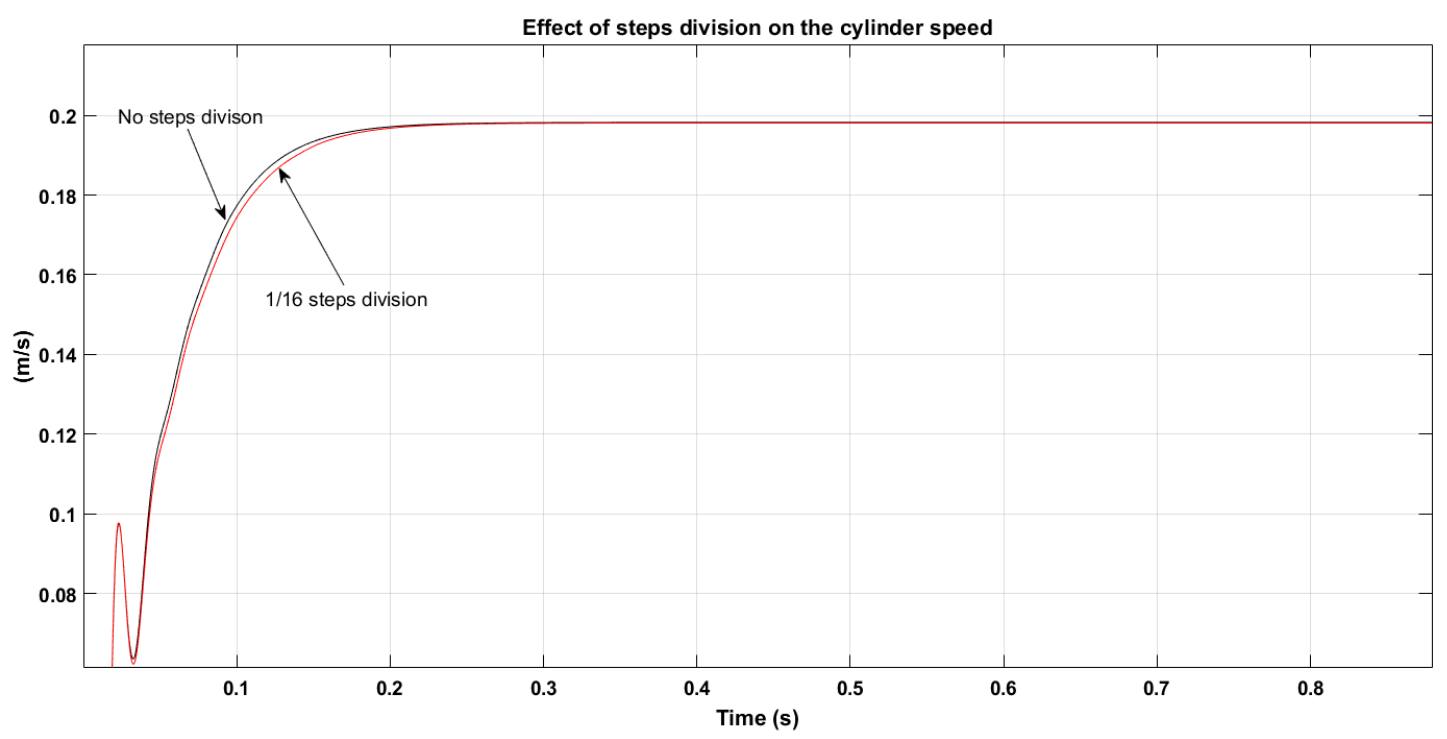

Fig. 10. The effect of the step division technique using the MIM configuration.

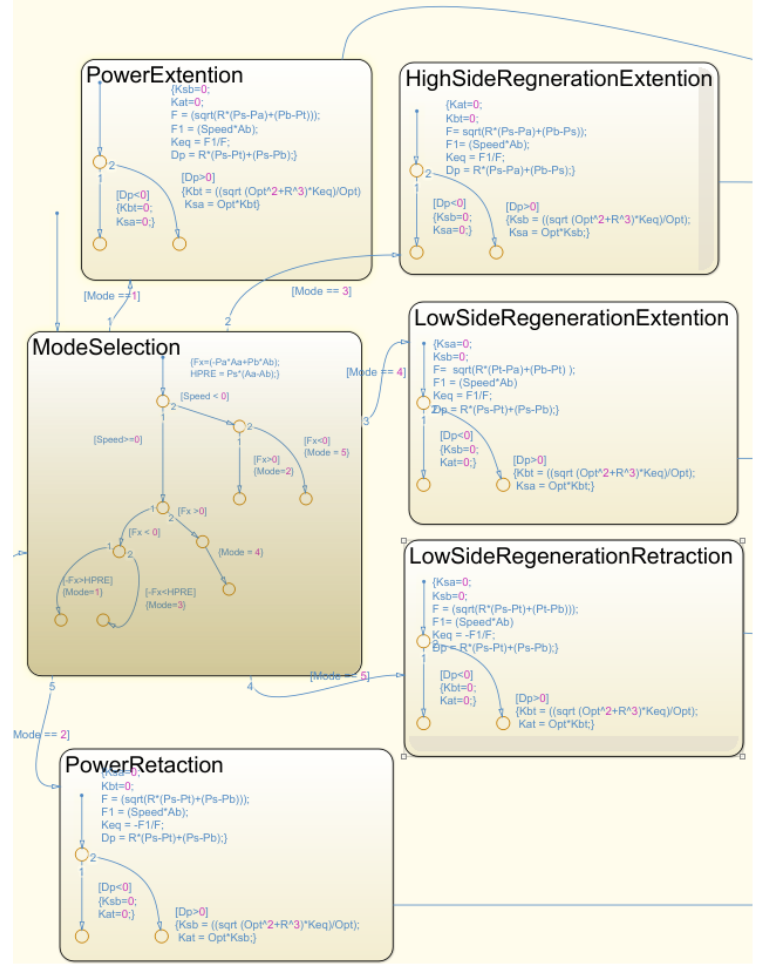

(a)

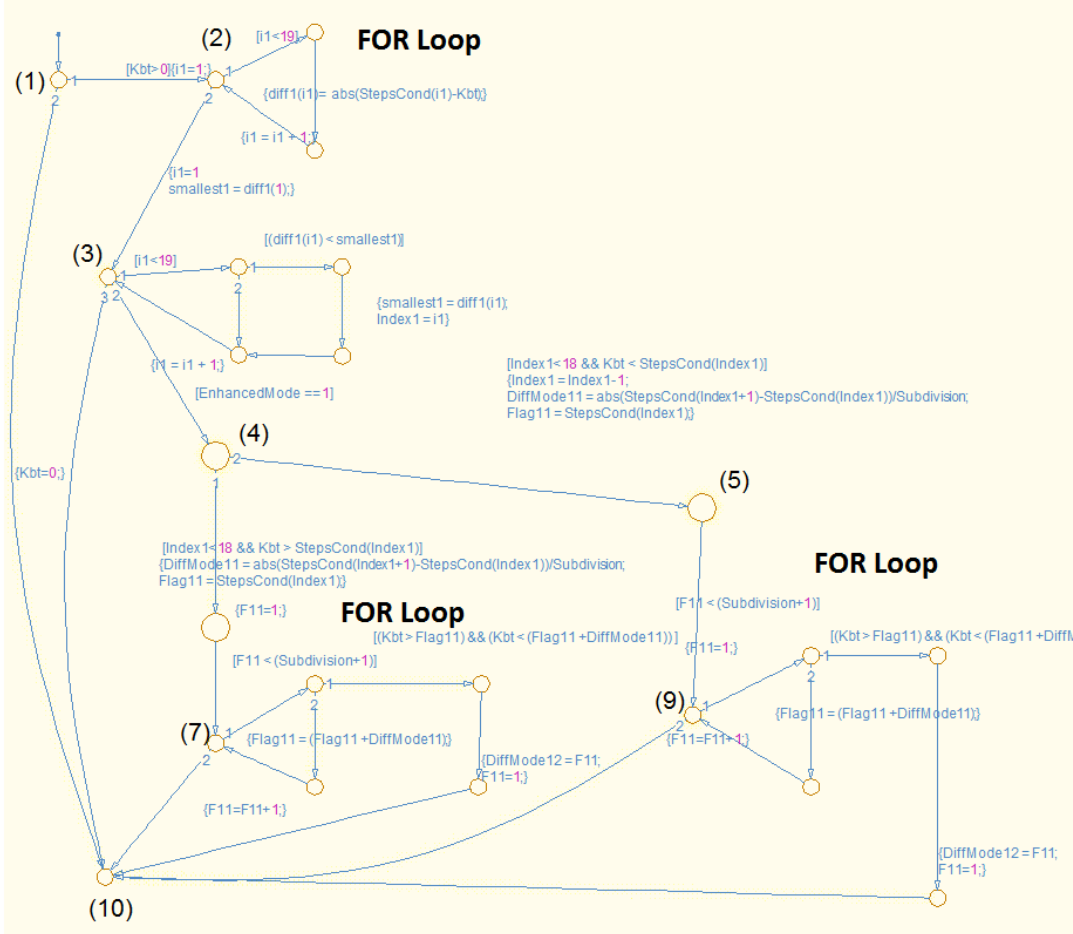

(b)

Fig. 11. The State-flow diagram of the mode selection sub-part (a) and the sub-part of every mode conductance calculation (b). 